\title{
First description and evaluation of SNPs in the ADH and ALDH genes in a population of alcoholics in Central-West Brazil
}

\author{
Thallita Monteiro Teixeira ${ }^{a}$, Hugo Delleon da Silva a , Rebeca Mota Goveia a, \\ Paulo Eduardo Martins Ribolla ${ }^{b}$, Diego Peres Alonso ${ }^{b}$, Alessandro Arruda Alves ${ }^{c}$, \\ Daniela Melo e Silva ${ }^{\text {c }}$, Rosane Garcia Collevatti ${ }^{\mathrm{d}}$, Lucilene Arilho Bicudo ${ }^{\mathrm{a}}$, \\ Nádia Aparecida Bérgamo ${ }^{\text {a }}$, Elisângela de Paula Silveira-Lacerda ${ }^{\text {a, * }}$ \\ ${ }^{a}$ Laboratório de Genética Molecular e Citogenética, Instituto de Ciências Biológicas, Universidade Federal de Goiás, Avenida Esperança, s/n, Campus \\ Samambaia (Campus II), Goiânia, GO, CEP: 74690-900, Brazil \\ ${ }^{\mathrm{b}}$ Laboratório de Pesquisa e Análises Genéticas, Instituto de Biociências de Botucatu, Universidade Estadual Paulista, Botucatu, São Paulo, Brazil \\ ${ }^{\mathrm{c}}$ Laboratório de Mutagênese, Instituto de Ciências Biológicas, Universidade Federal de Goiás, Goiânia, Brazil \\ ${ }^{\mathrm{d}}$ Laboratório de Genética e Biodiversidade, Instituto de Ciências Biológicas, Universidade Federal de Goiás, Goiânia, Brazil
}

\section{A R T I C L E I N F O}

Article history:

Received 29 September 2016

Received in revised form 7 April 2017

Accepted 11 April 2017

\section{Keywords:}

$\mathrm{ADH}$

Alcohol-use disorder

ALDH

Linkage disequilibrium

Polymorphism

\begin{abstract}
A B S T R A C T
Worldwide, different studies have reported an association of alcohol-use disorder (AUD) with different types of Single Nucleotide Polymorphisms (SNPs) in the genes for aldehyde dehydrogenase (ALDH) and alcohol dehydrogenase (ADH). In Brazil, there is little information about the occurrence of these SNPs in the AUD population and an absence of studies characterizing the population in the Central-West Region of Brazil. Actually, in Brazil, there are more than 4 million people with AUD. Despite the major health hazards of AUD, information on alcohol consumption and its consequences are not well understood. Therefore, it is extremely important to characterize these SNPs for the better understanding of AUD as a genetic disease in the Brazilian population. The present study, unlike other studies in other countries, is done with a subject population that shows a significant amount of racial homogenization. We evaluated the presence of SNPs in the ADH (ADH1B, ADH1C, and ADH4) and ALDH (ALDH2) genes in alcohol users of Goiânia, State of Goiás - Brazil, and then we established a possible relationship with AUD by allelic and genotypic study. This study was conducted with a population of people with AUD ( $n=99)$ from Goiás Alcohol Dependence Recovery Center (GO CEREA) and Psychosocial Care Center for Alcohol and Drugs (CAPS AD), and with a population of people without AUD as controls $(n=100)$. DNA was extracted from whole-blood samples and the genotyping was performed using TaqMan ${ }^{\circledR}$ SNP genotyping assays. For characterization and evaluation of SNPs in the population, genotype frequency, allele frequency, haplotype frequency, Hardy-Weinberg equilibrium, and linkage disequilibrium were analyzed. Statistical analyses were calculated by GENEPOP 4.5 and Haploview software. The allele 1 was considered as "wild" (or ${ }^{*} 1$ ) and allele 2 as mutant (or ${ }^{*} 2$ ). Significant differences were found for $A D H 1 B^{*}, A D H 4^{*} 2$, and $A L D H 2 * 2$ SNPs when the genotype and allele frequencies were analyzed. In addition, four haplotypes were observed between $A D H 1 B^{*} 2$ and $A D H 1 C^{*} 2$ through linkage disequilibrium analysis. The genetic variants may be associated with protection against AUD in the population studied.
\end{abstract}

(C) 2017 Elsevier Inc. All rights reserved.

\section{Introduction}

The use of alcohol and its psychosocial consequences is a major public health problem of modern societies (Meloni \& Laranjeira,

\footnotetext{
* Corresponding author. Tel.: +55 623521 1078; fax: +55 6235211190 .

E-mail address: elacerda@ufg.br (E. de Paula Silveira-Lacerda).
}

2004). With a population of 207,952,133 inhabitants (IBGE, 2016), the First National Survey on Alcohol Consumption in the Brazilian population revealed that $52 \%$ of Brazilians drank at least once in the previous year.

After ingestion, ethanol is completely absorbed by the membranes of the digestive tract, especially the stomach and proximal small intestine (Crabb, Matsumoto, Chang, \& You, 2004). The primary route of elimination of ethanol is by means of oxidation to 
acetaldehyde and subsequent transformation into acid and water. These reactions are catalyzed by the enzymes alcohol dehydrogenase $(A D H)$ and aldehyde dehydrogenase $(A L D H)$, respectively. Single Nucleotide Polymorphisms (SNPs) in these genes have been associated in most cases with a possible predisposition to alcoholuse disorder (AUD) (Higuchi, Matsushita, Murayama, Takagi, \& Hayashida, 1995). These polymorphisms may also serve as a protective factor against AUD (Borràs et al., 2000; Chambers et al., 2002; Chen et al., 1999; Neumark, Friedlander, Thomasson, \& Li, 1998; Wall, Shea, Luczak, Cook, \& Carr, 2005).

The $A L D H$ enzyme is mainly responsible for the oxidation of acetaldehyde (Kuo et al., 2008). Therefore, $A L D H 2{ }^{*} 2$ polymorphism carriers are unable to oxidize acetaldehyde, which causes severe hangover (Li et al., 2012). At moments of severe hangover, the individual can easily refuse the next drink of an alcoholic beverage, then decrease the alcohol consumption, and consequently reduce the risk of AUD (Dickson et al., 2006).

Currently, there are different international studies that correlate AUD with the occurrence of SNPs to $A D H$ and $A L D H$ genes; most of these studies were conducted in the Asian continent (Chiang et al., 2012; Lee, Chau, Yao, Wu, \& Yin, 2006; Peng et al., 2002; Vatansever et al., 2015). In Brazil, however, there has been little research on this correlation. No such studies have been conducted on the population from the Midwest region of Brazil. Brazilian studies about alcoholism and polymorphism are concentrated in São Paulo (Guindalini et al., 2005; Nishimoto et al., 2004), Rio de Janeiro (Rebello, Moura-Neto, \& Carvalho, 2011), and in the Amazon region (Rebello et al., 2011).

An estimated $12 \%$ of the adult general population in Brazil meet criteria for inclusion for AUD (Silveira et al., 2011). Despite this being a major public health problem, information on the consequences of alcohol consumption are not well-understood, so it is extremely important to characterize these SNPs to better understand the genetic contribution to AUD for adults in a populationbased sample in Goiânia, Central-West Region of Brazil. This region in particular is important to study because of the significant amount of racial homogenization, which is less observed in other regions of Brazil (Prado \& Caria, 2007). Such a study is unprecedented in the region of Goiás, and will contribute to a deeper understanding of the genetic contribution to susceptibility to AUD. This study will contribute to a better understanding of this pathology, and will help with preventive actions, such as genetic counseling.

This study characterizes the incidence of four SNPs, $A D H 1 B$ (rs1159918), ADH1C (rs1614972), ADH4 (rs1042364), and ALDH2 (rs2238151), in the population with AUD in the city of Goiannia. The specific aims were to: i) determine the genotype and allele frequencies, ii) determine pair-wise linkage disequilibrium, iii) characterize the different haplotypes present in the population, and iv) evaluate the phenotypic association with population genetic data.

\section{Materials and methods}

\section{Location study}

A case-control study was conducted at Centro de Recuperação de Alcóolatras/Goiás Alcohol Dependence Recovery Center (GO CEREA) and at Centro de Atenção Psicossocial Álcool e Drogas/ Psychosocial Care Center Alcohol and Drugs (CAPS AD), both in Goiânia city. The GO CEREA works with preventive measures awareness and recovery for people with AUD. CAPS AD is a specific service for comprehensive and continuing care of people who use alcohol, cocaine, and other drugs. CAPS AD offers 24-h services to the population, performs clinical follow-up, and assists with social reinsertion through work and recreation. The activities carried out encourage the strengthening of family and community ties, creating spaces for socialization.

\section{Inclusion criteria}

A signed written informed consent was obtained from all participants in this study, which was approved by the ethics committee of the Universidade Federal de Goiás (UFG) in accordance with The Code of Ethics of the World Medical Association (Declaration of Helsinki) for experiments involving humans.

From December 2014 to May 2015, we selected 99 patients diagnosed and confirmed with AUD in the GO CEREA and CAPS AD units, and 100 non-AUD subjects from a random sample at UFG, totaling 199 patients. All of these subjects answered the Free and Informed Consent Form, which contained physical and epidemiological data.

Individuals with AUD were defined as those who had received a specialized health service (specialized health centers) associated with mental illness and/or alcoholics' recovery, based on the standards set by DSM-IV (Diagnostic and Statistical Manual of Mental Disorders), which establishes the criteria for alcohol abuse (DSM-IV-TRTM, 2002). Control subjects were defined as individuals who were not suffering from AUD. They were chosen in accordance with a study by Salujha, Chaudhury, Menon, Srivastava, and Gupta (2014), in which the control population was interviewed in common sites such as universities, libraries, and churches.

\section{DNA extraction of samples and SNPs analysis by real-time PCR}

DNA was extracted from patient whole blood using a Pure Link Kit (Invitrogen ${ }^{\mathrm{TM}}$ ) and stored at $-80{ }^{\circ} \mathrm{C}$ until use. Subsequently, DNA concentration and purity were measured using a NanoDrop 2000c Spectrophotometer (Thermo Scientific). Genotyping for ADH1B (rs1159918/D: C__2688471_10), ADH1C (rs1614972/ID: C_8829593_10), ADH4 (rs1042364/ID: C__9523707_30), and ALDH2 (rs2238151/ID: C__339070_20) was performed using Custom TaqMan ${ }^{\mathbb{B}}$ SNP genotyping assays on a StepOnePlus тм RealTime PCR System (Applied Biosystems). The standard real-time polymerase chain reaction (qPCR) was carried out using TaqMan ${ }^{\mathbb{R}}$ Genotyping Master Mix (Catalog number: 4371353, Applied Biosystems) reagent kit in a $10-\mu \mathrm{L}$ volume, according to the manufacturer's instructions.

\section{Statistical analysis}

The allele and genotype frequencies were calculated to evaluate the differences between populations ( $p \leq 0.05$ ). Hardy-Weinberg equilibrium was also calculated, and statistical analyses were performed using the software GENEPOP (Rousset, 2008).

We calculated frequencies for the case $\times$ control and female $\times$ male analyses. In addition, the odds ratio (OR) was calculated for each genotype and compared between cases and controls (95\% confidence intervals for risk). The allele 1 was considered as "wild" (or *1) and allele 2 as mutant (or *2). We used Haploview version 3.2 for the analysis of linkage disequilibrium and to investigate haplotype diversity and frequency (Barrett, Fry, Maller, \& Daly, 2005).

The linkage disequilibrium (LD) is the non-random association of alleles at two or more loci. The LD describes a situation in which some combinations of alleles or genetic markers occur more or less frequently in a population than would be expected by random haplotype formation from alleles, based on their frequencies. The associations between polymorphisms were measured by the LD levels (Hartl \& Clark, 2007). 


\section{Results}

The data showed that the drinking habit was present in both populations (case and control), with $79 \%$ (157 individuals) of the total population who drank regularly. In the control population, $24 \%$ (24 individuals) of the subjects were male and 76\% (76 individuals) were female. In the case population, values observed were $84 \%$ ( 83 individuals) male and $16 \%$ (16 individuals) female. Initially, the allelic frequencies of each SNP were calculated in the total population studied (case and control). The allelic frequency data, such as the SNP Code (or SNP ID) chromosome SNP position, ancestral allele, and mutant allele (or polymorphism) are shown in Table 1.

We performed other polymorphism analysis by initially observing the allele and genotype frequencies of the SNP of the total population [case population (alcoholic individuals) and control population (individuals without AUD)] as shown in Table 2 below. Table 2 did not show a statistically significant difference $(p \leq 0.05)$ in the distribution of allele and genotype frequencies between case and control groups in any of these polymorphic variants that have been researched. Compared with the case subjects, the $A L D H 2 * 2$ SNP has been observed with greater frequency in the control subjects.

Comparing the case group with the control group, it was necessary to subdivide the case population. Therefore, we divided the case population into different subgroups according to

Table 1

Allele frequencies of each SNP in the total study population (Case + Control; $\mathrm{n}=199$ ), Goiânia, Brazil.

\begin{tabular}{lllll}
\hline SNP & SNP ID & $\begin{array}{l}\text { Chromosome } \\
\text { position }\end{array}$ & $\begin{array}{l}\text { Mutant } \\
\text { allele }\end{array}$ & $\begin{array}{l}\text { Mutant allele } \\
\text { frequency }\end{array}$ \\
\hline$A D H 1 B^{*} 2$ & rs1159918 & 99321852 & $\mathrm{~T}$ & $49 \%$ \\
$A D H 1 C^{*} 2$ & rs 1614972 & 99336998 & $\mathrm{~T}$ & $39 \%$ \\
$A D H 4^{*} 2$ & $\mathrm{rs} 1042364$ & 99124423 & $\mathrm{G}$ & $25 \%$ \\
$A L D H 2^{*} 2$ & $\mathrm{rs} 2238151$ & 111774029 & $\mathrm{~T}$ & $48 \%$ \\
\hline
\end{tabular}

epidemiological data: sex/gender, age, race, profession, schooling, tobacco use, and amount of alcohol ingested (data not shown). However, only one analysis shows a statistically significant difference ("Female vs. Male"), as shown in Table 3.

In Table 3, a statistically significant difference was observed for the allele $(p=0.01)$ and genotype $(p<0.01)$ frequencies for the $A D H 4^{*} 2$ SNP among AUD patients. However, for the other SNPs, with the exception of $A L D H 2^{*} 2$ (significant difference in allele frequency between the genders), there was no statistically significant difference in allele and genotype frequencies.

After the analyses of the allele and genotype frequencies, a linkage disequilibrium analysis of the SNPs that belong to the same gene family $\left(A D H 1 B^{*} 2, A D H 1 C^{*} 2\right.$, and $\left.A D H 4^{*} 2\right)$ were also conducted, as shown in Figure 1 . The $A D H 4^{*} 2$ gene is represented by the numeral 1, the $A D H 1 B$ gene is represented by the numeral 2 , and the $A D H 1 C^{*} 2$ gene is represented by the numeral 3 .

The three genes analyzed are close together, when the distance (in base pairs) between SNPs in the HapMaps was observed. However, this proximity becomes greater when looking at SNPs $A D H 1 B^{*} 2$ (2) and $A D H 1 C^{*} 2(3)$, which are separated by only 15,146 base pairs. Nevertheless, in the LD analysis a strong connection between $A D H 4$ (1) and $A D H 1 B$ (2) was observed, which is represented by the $L O D$ ( $\log$ of the likelihood odds ratio) score of 6.23 and $D^{\prime}$ score of 0.8 . Strong colors, such as the red one, indicate high $D^{\prime}$ values (the maximum is 1 ). The "r squared" represents a low score (0.297).

From this LD analysis, haplotypes from dependent segregations on these $A D H 4$ and $A D H 1 B$ genes in the case population were generated, as shown in Table 4, which shows four haplotype loci formed in the case population: CA, CC, TC, TA, with the corresponding frequencies of $50,24,25$, and $1 \%$, respectively.

After the haplotype analysis, it was possible to establish the frequency of the observed homozygosity $(\mathrm{Ho})$ and expected heterozygosity $(\mathrm{He})$ in the population, beyond the minimum allele frequency (MAF), as shown in Table 5.

Genotype-phenotype relationships between genetic polymorphisms in the case and control populations were evaluated

Table 2

Allele and genotype frequencies of the four SNPs $\left(A D H 1 B^{*} 2, A D H 1 C^{*} 2, A D H 4^{*} 2, A L D H 2 * 2\right)$ in a population-based case-control study in the city of Goiânia, Brazil.

\begin{tabular}{|c|c|c|c|c|c|c|c|c|c|c|c|c|}
\hline \multirow[t]{3}{*}{ SNP ID/SNP } & \multicolumn{5}{|c|}{ Allele frequency } & \multicolumn{7}{|c|}{ Genotypic frequency } \\
\hline & \multicolumn{2}{|c|}{ Case $(\mathrm{n}=99)$} & \multicolumn{2}{|c|}{ Control $(\mathrm{n}=100)$} & \multirow[t]{2}{*}{$p$ value } & \multicolumn{3}{|c|}{ Case $(\mathrm{n}=99)$} & \multicolumn{3}{|c|}{ Control $(n=100)$} & \multirow[t]{2}{*}{$p$ value } \\
\hline & Allele 1 & Allele 2 & Allele 1 & Allele 2 & & $* 1 /{ }^{*} 1$ & $* 1 / * 2$ & ${ }^{*} 2 /{ }^{*} 2$ & ${ }^{*} 1 /{ }^{*} 1$ & ${ }^{*} 1 /{ }^{*} 2$ & $* 2 / * 2$ & \\
\hline rs1159918 $\left(A D H 1 B^{*} 2\right)$ & $50.51 \%$ & $49.49 \%$ & $51.61 \%$ & $48.39 \%$ & 0.83 & $22 \%$ & $57 \%$ & $21 \%$ & $21 \%$ & $54 \%$ & $18 \%$ & 0.82 \\
\hline rs1614972 (ADH1C 2$)$ & $59.90 \%$ & $40.10 \%$ & $63.44 \%$ & $36.56 \%$ & 0.53 & $29 \%$ & $58 \%$ & $10 \%$ & $34 \%$ & $50 \%$ & $9 \%$ & 0.48 \\
\hline rs1042364 $\left(A D H 4^{*} 2\right)$ & $73.47 \%$ & $26.53 \%$ & $76.87 \%$ & $23.13 \%$ & 0.52 & $51 \%$ & $44 \%$ & $4 \%$ & $37 \%$ & $29 \%$ & $1 \%$ & 0.48 \\
\hline rs2238151 (ALDH2*2) & $54.43 \%$ & $45.57 \%$ & $50.55 \%$ & $49.45 \%$ & 0.51 & $16 \%$ & $55 \%$ & $9 \%$ & $25 \%$ & $42 \%$ & $24 \%$ & 0.48 \\
\hline
\end{tabular}

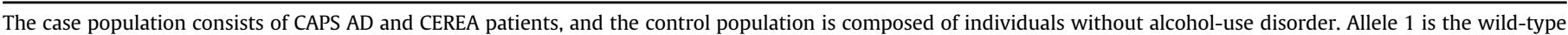
allele; allele 2 is responsible for the mutation, being named as the mutant allele; " $n$ " represents the individuals' numbers in each group.

Chi-squared test.

Table 3

Allele and genotype frequencies of distribution in the case population when matched by gender (Female vs. Male).

\begin{tabular}{|c|c|c|c|c|c|c|c|c|c|c|c|c|}
\hline \multirow[t]{3}{*}{ SNP ID/gene } & \multicolumn{5}{|c|}{ Allele frequency } & \multicolumn{7}{|c|}{ Genotypic frequency } \\
\hline & \multicolumn{2}{|c|}{ Female $(n=15)$} & \multicolumn{2}{|c|}{ Male $(\mathrm{n}=84)$} & \multirow[t]{2}{*}{$p$ value } & \multicolumn{3}{|c|}{ Female $(n=15)$} & \multicolumn{3}{|c|}{ Male $(\mathrm{n}=84)$} & \multirow[t]{2}{*}{$p$ value } \\
\hline & Allele 1 & Allele 2 & Allele 1 & Allele 2 & & ${ }^{*} 1 /{ }^{*} 1$ & ${ }^{*} 1 / * 2$ & $* 2 / * 2$ & ${ }^{*} 1 /{ }^{*} 1$ & ${ }^{*} 1 /{ }^{*} 2$ & $* 2 / * 2$ & \\
\hline rs1159918 (ADH1B*2) & $40.63 \%$ & $59.38 \%$ & $51.81 \%$ & $48.19 \%$ & 0.33 & $6 \%$ & $69 \%$ & $25 \%$ & $25 \%$ & $53 \%$ & $22 \%$ & 0.30 \\
\hline rs1614972 (ADH1C*2) & $63.33 \%$ & $36.67 \%$ & $56.26 \%$ & $40.74 \%$ & 0.69 & $27 \%$ & $73 \%$ & $0 \%$ & $31 \%$ & $57 \%$ & $12 \%$ & 0.65 \\
\hline rs1042364 $\left(A D H 4^{*} 2\right)$ & $53.33 \%$ & $46.67 \%$ & $76.51 \%$ & $23.49 \%$ & 0.01 & $27 \%$ & $53 \%$ & $20 \%$ & $55 \%$ & $42 \%$ & $3 \%$ & $<0.01$ \\
\hline rs2238151 (ALDH2*2) & $71.43 \%$ & $28.57 \%$ & $51.54 \%$ & $48.46 \%$ & 0.06 & $50 \%$ & $43 \%$ & $7 \%$ & $15 \%$ & $72 \%$ & $13 \%$ & 0.01 \\
\hline
\end{tabular}

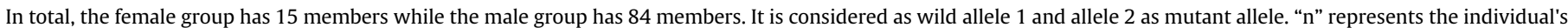
number in each group, and p values less than 0.05 have been highlighted in bold italics.

Chi-squared test. 


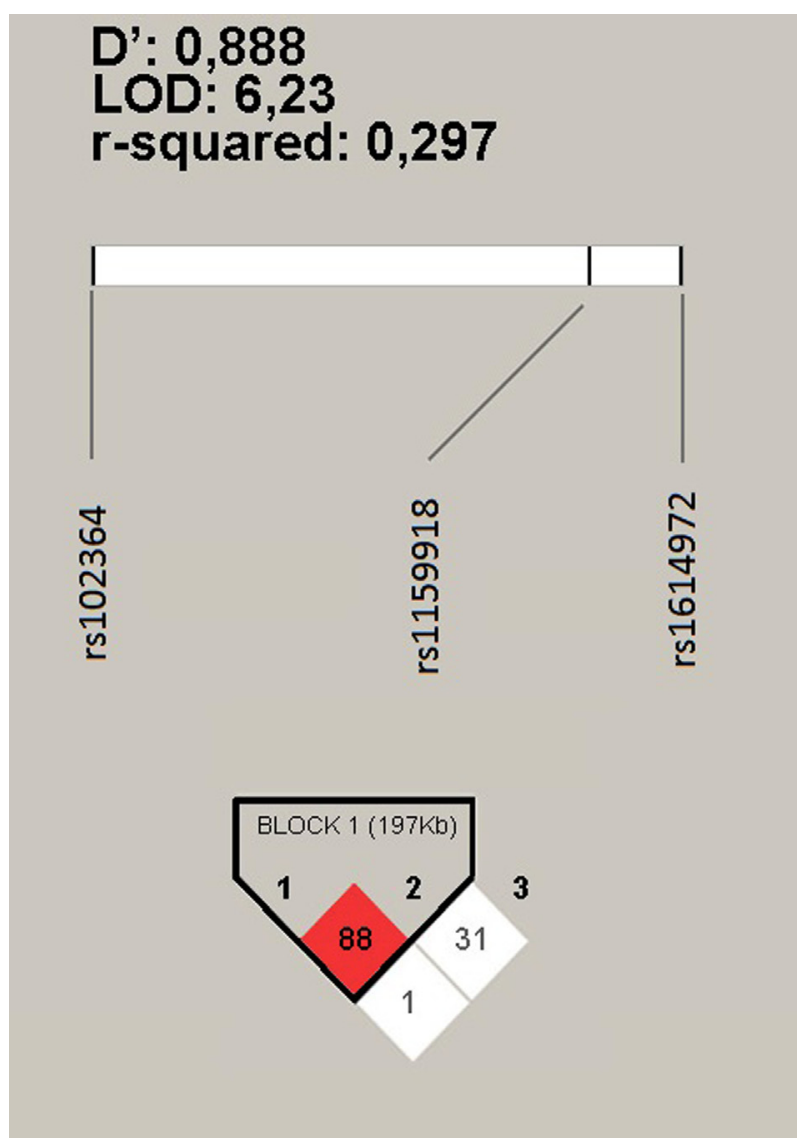

Fig. 1. HapMap with Linkage disequilibrium analysis for SNPs present in genes ADH1B, ADH1C, and ADH4.

Table 4

Haplotypic frequency distribution formed from $A D H 1 B$ and $A D H 4$ genes in the case population of Goiânia city $(\mathrm{n}=99)$.

\begin{tabular}{lll}
\hline$A D H 4^{*} 2$ SNP & $A D H 1 C^{*} 2$ SNP & Haplotype frequency \\
\hline Allele & Allele & Case population \\
C & A & $50 \%$ \\
C & C & $24 \%$ \\
$\mathrm{~T}$ & $\mathrm{C}$ & $25 \%$ \\
$\mathrm{~T}$ & $\mathrm{~A}$ & $1 \%$ \\
\hline
\end{tabular}

Case population: individuals with alcohol-use disorder who received a specialized health service (specialized health centers) associated with mental illness and/or alcoholics' recovery.

Table 5

Observed and expected heterozygosity and minimum allele frequency in the case population (sampling of individuals with alcohol-use disorder in the city of Goiânia).

\begin{tabular}{llllll}
\hline SNP & SNP ID & Ho & He & HWpValue & MAF \\
\hline$A D H 1 C^{*} 2$ & rs1614972 & $59 \%$ & $48 \%$ & 0.0383 & $40.1 \%$ \\
$A D H 1 B^{*} 2$ & rs1159918 & $57 \%$ & $50 \%$ & 0.2423 & $49.0 \%$ \\
$A D H 44^{*} 2$ & rs1042364 & $45 \%$ & $39 \%$ & 0.2266 & $26.5 \%$ \\
\hline
\end{tabular}

He: Expected heterozygosity (He); Ho: Observed heterozygosity; HWpValue: Hardy-Weinberg Equilibrium $p$ value; MAF: Minimum allele frequency.

using odds ratio (OR), and led to the most comprehensive study, as shown in Table 6. OR values for the genes ADH1C rs1614972, ADH1B rs1159918, ADH4 rs1042364 e, and ALDH2 rs2238151 were respectively: 1.33 (0.76-2.44), 1.02 (0.52-2.01), 1.18 (0.63-2.21), and $1.49(0.73-3.05)$ (confidence interval $=$ IC 95\%).
Table 6

Genotypic frequency in case and control populations, $p$ value and odds ratio (OR).

\begin{tabular}{|c|c|c|c|c|c|c|}
\hline \multirow[t]{2}{*}{ Genotype } & \multicolumn{2}{|c|}{ Controls } & \multicolumn{2}{|c|}{ Case } & \multirow[t]{2}{*}{$p$ value $^{a}$} & \multirow{2}{*}{$\begin{array}{l}\text { Odds ratio } \\
(95 \% \mathrm{CI})\end{array}$} \\
\hline & $\mathrm{N}$ & $\%$ & $\mathrm{~N}$ & $\%$ & & \\
\hline \multicolumn{7}{|c|}{ ADH1C rs1614972 } \\
\hline $\mathrm{CC}$ & 34 & $(36.6 \%)$ & 29 & $(30.2 \%)$ & \multirow[t]{2}{*}{0.355} & 1.00 (Reference) \\
\hline $\mathrm{CT} / \mathrm{TT}$ & 59 & $(63.4 \%)$ & 67 & $(69.8 \%)$ & & $1.33(0.76-2.44)$ \\
\hline \multicolumn{7}{|c|}{ ADH1B rs1159918 } \\
\hline GG & 21 & $(22.6 \%)$ & 22 & $(22.2 \%)$ & \multirow[t]{2}{*}{0.953} & 1.00 (Reference) \\
\hline GT/TT & 72 & (77.4\%) & 77 & (77.8\%) & & $1.02(0.52-2.01)$ \\
\hline \multicolumn{7}{|c|}{ ADH4 rs1042364 } \\
\hline AA & 37 & $(55.2 \%)$ & 50 & $(51.0 \%)$ & \multirow[t]{2}{*}{0.595} & 1.00 (Reference) \\
\hline AG/GG & 30 & $(44.8 \%)$ & 48 & $(49.0 \%)$ & & $1.18(0.63-2.21)$ \\
\hline \multicolumn{7}{|c|}{ ALDH2 rs2238151 } \\
\hline $\mathrm{CC}$ & 25 & $(27.5 \%)$ & 16 & $(20.3 \%)$ & \multirow[t]{2}{*}{0.274} & 1.00 (Reference) \\
\hline $\mathrm{CT} / \mathrm{TT}$ & 66 & $(72.5 \%)$ & 63 & (79.8\%) & & $1.49(0.73-3.05)$ \\
\hline
\end{tabular}

Distribution of genotypes among case and control patients.

a Based on Chi-square test. The significant values are represented in bold.

\section{Discussion}

While Bienarcka et al. (2013) have genotyped only one or two SNPs per gene in a Brazilian population, in our work we investigated the association of other $A D H$ SNPs with AUD and related phenotypes, and we also investigated the association of SNPs in LD.

We found that the drinking habit was present in both populations (case and control), and $79 \%$ of the total population drink, even if occasionally. Furthermore, in our study we observed that most of the case individuals were male, and in the control group, most of the subjects were female. This inverse proportion had been previously observed in a study conducted in Rio de Janeiro, Brazil (Rebello \& Carvalho, 2008).

Despite many studies that contemplate the analyses of SNPs $A D H 1 B^{*} 2, A D H 1 C^{*} 2, A D H 4^{*} 2$ e, and $A L D H 2 * 2$ in individuals from different states of Brazil (Guindalini et al., 2005; Rebello et al., 2011), there are no reports thus far with data of the allele and genotype frequency of these individuals in the population here evaluated. So, it is possible to correlate the frequency data of the population obtained in this study with the frequency data from the populations in which the population profile is closer to the overall Brazilian population, as, for example, the African-American population.

Within the worldwide distribution, the polymorphism $A D H 1 B^{*} 2$ has a frequency of $78.6 \%$ in the African-American population, showing a prevalence of the mutant allele in most of this population (DataBase SNP, 2015). In this study, there was a frequency of $50 \%$ for this same SNP. That is, for the Goiânia alcoholic population, the frequency of the mutant allele is reduced compared to the previous study (Rebello et al., 2011). The $A D H 1 C^{*} 2$ polymorphism has an allelic frequency of $56.2 \%$ in the African-American population (DataBase SNP, 2015). Here, we observed a frequency of $40 \%$ in the Goiânia alcoholic population.

The $A D H 4^{*} 2$ polymorphism has a frequency of $14.3 \%$ in the African-American population (DataBase SNP, 2015), compared to a frequency of $26 \%$ observed in the Goiânia alcoholic population, which is a higher frequency than was observed in previous studies. The results show an association of the gene polymorphism that can shed light on the origin and development of alcoholism. This work strongly supports the hypothesis that $A D H 4$ is a gene for susceptibility to development of alcoholism (Edenberg et al., 2006; Turchi et al., 2012).

The $A L D H 2 * 2$ polymorphism has a frequency of $15.2 \%$ in the African-American population (DataBase SNP, 2015). Here, we observed a frequency of $46 \%$ in the Goiânia alcoholic population; it also has a higher frequency compared to the value obtained by Macgregor et al. (2009). 
Statistically significant differences in the distribution of allelic frequencies between case and control groups were not found. This result is corroborated by the study by Rebello and Carvalho (2008). There was no statistically significant difference when the analysis of ADH1C SNP $\left(A D H 1 C^{*} 2\right)$ was made in a population of members of Alcoholics Anonymous (AA) and a "control" group from the city of Rio de Janeiro. Statistically significant differences were not found in the genotype frequencies for $A D H 4^{*} 2, A D H 1 B^{*} 2, A D H 1 C^{*} 2$, and $A L D H 2 * 2$ polymorphic variants. Those results are contradictory when compared with other studies where these polymorphisms have already been related to susceptibility to alcoholism and protection from alcoholism, respectively (Hakenewerth et al., 2011; Meyers et al., 2015; Preuss et al., 2011; Wang et al., 2014).

Although no statistically significant difference was observed among the SNPs evaluated, the $A L D H 2 * 2$ SNP in homozygosity showed a greater frequency in the control population, with a percentage of $24 \%$, while in the case population this percentage was in only $9 \%$ of the individuals. This can be explained by the fact that the $A L D H 2 * 2$ allele causes the accumulation of acetaldehyde in the blood - it is what protects the individual from alcoholism (Peng et al., 2002). $A L D H 2^{*} 2$, especially in homozygous individuals, promotes a rapid "flushing" of the face after drinking alcohol. This phenomenon occurs in $80 \%$ of Asian individuals, contributing to a lower incidence of alcoholism in this population (Brooks, Goldman, \& Li, 2009; Macgregor et al., 2009). The occurrence of the $A L D H 2 * 2$ polymorphism in a higher frequency in the control group (compared to the case group) presents itself as a fundamental genetic characteristic of this population. This SNP, which helps prevent the development of alcohol-use disorder, is not necessarily found in groups of individuals with high rates of alcohol-use disorder.

A study conducted by Dickson et al. (2006) reported a higher frequency of this polymorphism in control individuals when compared with a group of individuals with alcohol-use disorder. Furthermore, Dickson et al. (2006) showed that individuals who were homozygous for this polymorphism had less risk (very low) for the development of alcoholism than individuals who were heterozygous for this polymorphism.

It is important to note that data related to the symptoms resulting from the abuse of alcohol were not initially collected during the recruitment of these individuals for participation in the study. This fact is relevant to future studies that may investigate the factors related to alcoholism, where relevant data, such as the clinical manifestations resulting from alcoholic beverage consumption, may be considered highly important to the evaluation of the genetic components contributing to the development of alcohol-use disorder.

Therefore, the present study presents a new perspective by the strong evidence that $A D H 4^{*} 2 \mathrm{SNP}$ is highly correlated to susceptibility for alcoholism development, and that the $A D H 1 C^{*} 2, A D H 1 B^{*} 2$, and $A L D H 2 * 2$ SNPs are highly correlated with protection against development of alcoholism.

Our data showed a statistically significant difference in the distribution of alleles for the $A D H 4^{*} 2$ polymorphic variant, as had already been observed by Luo et al. (2006) in a European population. Additionally, $A D H 4^{*} 2$ polymorphism showed a significant difference in prevalence when studied in a population of Brazilians from Sao Paulo city, and was related to the risk of alcoholism (Guindalini et al., 2005). It is believed that individuals who are homozygous for SNP $A D H 4^{*} 2$ are at greater risk of developing alcoholism than those who do not carry this polymorphism.

Statistically significant differences in the genotype distribution for $A D H 4^{*} 2(p<0.01)$ and for $A L D H 2 * 2(p=0.01)$ SNP can be observed in the case population when matched by gender. In studies by Macgregor et al. (2009) and Luo et al. (2006), significant differences were observed and studied in a population of people with alcoholism from the state of Connecticut in the United States. It is suggested, therefore, that the individuals who were carriers of the $A D H 4^{*} 2$ polymorphic variant can be more susceptible to developing alcoholism and that individuals who were carriers of the $A L D H 2 * 2$ polymorphic variant can be protected against alcoholism. It is important to emphasize in this study that there was a much greater consumption of alcohol by men than by women, as was also reported by Cardoso, Melo, and Cesar (2015). This is possibly due to long-established cultural patterns.

The LD between each SNP was calculated from three measures: LOD score, $D^{\prime}$ (standard deviation coefficient), and the $r^{2}$ value. The $L O D$ ( $\log$ of the Odds) score method compares the probability of the data being obtained if the two loci are truly connected and the probability of observing the same data by chance (random). The program considers that $L O D>2$ indicates a significant LD (Hartl \& Clark, 2007).

The $D^{\prime}$ coefficient depends on the allele frequencies, and its value varies from a negative value to a positive value. The coefficient of determination value $\left(r^{2}\right)$ represents the correlation coefficient in the allelic state between the alleles in the same gamete. $r^{2}$ ranges from 0 to 1 . The value is 1 when the two markers provide identical information and the value is 0 when they are in perfect equilibrium. Both measures, $D^{\prime}$ and $r^{2}$, are used to describe the amount of the LD because they represent different views of the gametic associations. Therefore, when $D^{\prime}$ is close to zero, $r^{2}$ also is close to zero. However, as $D^{\prime}$ increases, $r^{2}$ can be any value between zero and $\left(D^{\prime}\right)^{2}$ (Hartl \& Clark, 2007). As the genes are closer, the chances are greater of these genes segregating dependently and then forming haplotypes.

Bienarcka et al. (2013) tried to associate the $A D H 1 C^{*} 2$ SNP with AUD. However, in our work we associated this SNP and two other SNPs ( $A D H 1 B^{*} 2$ and $\left.A D H 1 C^{*} 2\right)$ with protection against alcoholism. As shown in Figure 1, a moderate connection between $A D H 1 C^{*} 2$ and $A D H 1 B^{*} 2$ SNPs was observed. Therefore, the distance between the SNPs (in base pairs) does not necessarily prove that there is a higher LD. From that LD, a formation of four haplotypes occurs in the population. The formation of these haplotypes indicates that segregation of genes during crossing-over rarely occurs, so that these genes are segregating dependently (Hartl \& Clark, 2007). The probability of one population to present a determined LD block structure is correlated with the details of its demographic history (Stumpf \& Goldstein, 2003). Knowing that both SNPs are responsible for protecting the individual against alcoholic dependency, the occurrence of these haplotypes in a certain portion of the population then shows that individuals with these haplotypes are less likely to develop alcohol-use disorder than individuals who do not have any of the haplotypes.

Through the haplotype frequencies obtained from LD analysis, they observed four different haplotypes occurring in the population. These haplotypes are CA, CC, TC, and TA. Their haplotype frequencies were $49,27,22$, and $2 \%$, respectively. Nevertheless, the use of the haplotypes containing many SNPs increases LD detection (Jorde, 2000). The CA haplotype is the most frequently represented (almost half of the study population), and its occurrence gives its carriers greater protection against alcoholism compared to individuals who do not carry this haplotype. However, in the case population, the CA has a frequency of $50 \%$, as opposed to a frequency of $47 \%$ in the control population.

Based on the Observed Heterozygosity (Ho), Expected Heterozygosity (He), and minimum allele frequency (MAF), the Ho reflects the amount of heterozygous individuals in a determined population and He indicates the probability of an individual to be heterozygous in loci, according to allele frequencies. Within the frequencies analyzed, both populations are in Hardy-Weinberg 
equilibrium.

When analyzing the minimum allele frequency (MAF) percentage of the studied population, a higher frequency percentage of SNP $A D H 1 B^{*} 2(49 \%)$ can be observed. SNPs with MAF percentages higher than $10-20 \%$ are the most indicated for LD studies, according to Service, Sabatti, and Freimer (2007), because they decrease the variability of the statistics (Weiss \& Clark, 2002), and make the determination of LD more realistic (Stenzel et al., 2004).

With the Ho and He values, it can be established whether or not there is a difference. For the null hypothesis (no difference) to be correct, the $p$ value must be equal to or greater than the $\alpha$ value (0.05). It is observed that in the polymorphic variant of the gene $A D H 1 B$, there is no difference between Ho and He. A difference between $\mathrm{Ho}$ and He was observed for the other polymorphic variants, which indicates that both populations studied have different genetic characteristics, and suggests that this population is under the influence of natural selection or other evolutionary factors (Freeland \& Petersen, 2011). Furthermore, as the MAF occurred more often to SNP $A D H 1 B^{*} 2$ SNP, this SNP has a greater frequency in the population studied.

The genotype frequencies of $A D H 1 C, A D H 1 B, A L D H 2$, and $A D H 4$ polymorphisms between case and control groups are shown in Table 6. Among the four SNPs investigated, the standard genotype was differentially distributed between alcoholics and nonalcoholics, and the value of $p$ was not significant in either group.

For the $A D H 1 C$ gene, the percentage of $C C$ and $C T / T T$ genotypes was $36.6 \%$ and $63.4 \%$ for controls, and $30.2 \%$ and $69.8 \%$ for the case group. The CT/TT genotype was more frequent in the case group than in the control group.

For the $A D H 1 B$ gene, the GG or GT/TT genotypes percentage was $22.6 \%$ and $77.4 \%$ for the control group, and $22.2 \%$ and $77.8 \%$ for the case group. The GT/TT genotype was more frequent in the case group than in the control group.

For the ADH4 gene, the percentage of AA or AG/GG genotypes was $55.2 \%$ and $44.8 \%$ for the control group, and $51.0 \%$ and $49.0 \%$ for the case group. The AA genotype was more common in the control group than in the case group.

For the $A L D H 2$ gene, the percentage of CC or CT/TT genotypes was $27.5 \%$ and $72.5 \%$ for the control group, and $20.3 \%$ and $79.8 \%$ for the case group. The CT/TT genotype was more frequent in the case group than in the control group. After this genotype analysis, the Odds Ratio (OR) was analyzed to discover a greater or lesser chance of triggering the disease.

For the OR analysis, the frequency distribution of genotypes indicates that individuals of the CT/TT genotype in ALDH2 (rs2238151) are more likely to be resistant to the development of alcohol-use disorder, corroborating the hypothesis that this SNP is associated with protection against alcohol-use disorder.

All subjects in this study will be informed about the results of the analyses and their impact on the health and life quality of the subjects. This activity will be done together with the professionals located in the centers used as reference (CAPS AD and GO CEREA). This study can be utilized as a tool to help with the treatment of these patients.

\section{Conclusion}

Despite some limitations such as the small sample size, especially for the number of women, we may address some strengths of our study. We observed an association between $A D H 1 C^{*} 2$ and $A L D H 2 * 2$ polymorphic variants with protection against the development of AUD, and we observed that the $A D H 4^{*} 2$ polymorphic variant is associated with susceptibility to development of alcoholuse disorder in the population studied in the city of Goiania, GO,
Brazil.

In our study, we found that an imbalance in the linkage is present between the SNPs $A D H 1 B^{*} 2$ and $A D H 1 C^{*} 2$, and that this imbalance occurs in a moderate form. Additionally, we found that four distinct haplotypes occur in the population (CA, CC, TC, and TA) and that $C A$ is the most frequent haplotype analyzed. The individuals carrying the haplotype CA are less susceptible to developing alcohol-use disorder, when compared to individuals who are not carriers of this haplotype. These data may be useful in counseling practices in systematic and individualized treatment, optimization of screening campaigns, and alcohol-use disorder prevention.

It was difficult to obtain a large number of individuals for this study. Although the participants' names and identities were not disclosed, some potential participants were afraid of exposing themselves to society. Thus, it is not uncommon for some studies to work with smaller samples, such as Kimura et al. (2009), which analyzed the polymorphisms in the promoter region of the ADH4 gene and its effect both on transcriptional activity and ethanol metabolism in 102 Japanese subjects, with only three female participants.

Another limitation is an intense mixture of factors present in Brazil, taking into account all the historical factors that exist in Brazil. Our study does not intend to assess the ethnic stratification, because these data are complex and include many variables to study. Further studies on the combination of SNPs and the mixture of genetic and environmental interactions with higher numbers of participants are necessary to address the increasing public health problem of alcohol-use disorder in Brazil.

\section{Conflicts of interest}

The authors declare no conflicts of interest.

\section{Acknowledgments}

The authors gratefully acknowledge the financial support from FAPEG (006/2012 - Process number: 2012102670001220). They would also like to thank the Coordination for the Advancement of Higher Education Staff (CAPES) for the fellowship to Thallita Monteiro Teixeira.

\section{References}

Barrett, J. C., Fry, B., Maller, J., \& Daly, M. J. (2005). Haploview: Analysis and visualization of LD and haplotype maps. Bioinformatics, 21, 263-265. https:/ doi.org/10.1093/bioinformatics/bth457.

Bienarcka, J. M., Geske, J. R., Schneekloth, T. D., Frye, M. A., Cunningham, J. M. Choi, D. S., et al. (2013). Replication of genome wide association studies of alcohol dependence: Support for association with variation in ADH1C. PLoS One, 8, e58798. https://doi.org/10.1371/journal.pone.0058798.

Borràs, E., Coutelle, C., Rosell, A., Fernández-Muixi, F., Broch, M., Crosas, B., et al (2000). Genetic polymorphism of alcohol dehydrogenase in Europeans: The ADH2*2 allele decreases the risk for alcoholism and is associated with ADH3*1. Hepatology, 31, 984-989. https://doi.org/10.1053/he.2000.5978.

Brooks, P. J., Goldman, D., \& Li, T. K. (2009). Alleles of alcohol and acetaldehyde metabolism genes modulate susceptibility to oesophageal cancer from alcohol consumption. Human Genomics, 3, 103-105.

Cardoso, L. G., Melo, A. P., \& Cesar, C. C. (2015). Prevalence of moderate and excessive alcohol consumption and associated factors among residents of Quilombo Communities (hinterland settlements founded by people of African origin) of Vitória da Conquista, Bahia, Brazil. Ciencia \& Saude Coletiva, 20, 809-820. https://doi.org/10.1590/1413-81232015203.12702014.

Chambers, G. K., Marshall, S. J., Robinson, G. M., Maguire, S., Newton-Howes, J., \& Chong, N. L. (2002). The genetics of alcoholism in Polynesians: Alcohol and aldehyde dehydrogenase genotypes in young men. Alcoholism: Clinical and Experimental Research, 26, 949-955. https://doi.org/10.1097/01.ALC.00000 21145.47616.38.

Chen, C. C., Lu, R. B., Chen, Y. C., Wang, M. F., Chang, Y. C., Li, T. K., et al. (1999). Interaction between the functional polymorphisms of the alcohol metabolism genes in protection against alcoholism. American Journal of Human Genetics, 65 
795-807. https://doi.org/10.1086/302540.

Chiang, C. P., Wu, C. W., Lee, S. P., Ho, J. L., Lee, S. L., Nieh, S., et al. (2012). Expression pattern, ethanol-metabolizing activities, and cellular localization of alcohol and aldehyde dehydrogenases in human small intestine. Alcoholism: Clinical and Experimental Research, 36, 2047-2058. https://doi.org/10.1111/j.15300277.2012.01836.x.

Crabb, D. W., Matsumoto, M., Chang, D., \& You, M. (2004). Overview of the role of alcohol dehydrogenase and aldehyde dehydrogenase and their variants in the genesis of alcohol-related pathologies. The Proceedings of the Nutrition Society, 63, 49-63.

Database SNP (dbSNP) (2015). https://www.ncbi.nlm.nih.gov/snp.

Dickson, P. A., James, M. R., Heath, A. C., Montgomery, G. W., Martin, N. G., Whitfield, J. B., et al. (2006). Effects of variation at the ADLH2 locus on alcohol metabolism, sensitivity, consumption, and dependence in Europeans. Alcoholism: Clinical and Experimental Research, 30, 1093-1100. https://doi.org 10.1111/j.1530-0277.2006.00128.x.

DSM-IV-TRTM. (2002). Manual diagnóstico e estatístico de transtornos mentais. trad. Cláudia Dornelles; - 4th ed. rev. Porto Alegre: Artmed

Edenberg, H. J., Xuei, X., Chen, H. J., Tian, H., Wetherill, L. F., Dick, D. M., et al. (2006) Association of alcohol dehydrogenase genes with alcohol dependence: A comprehensive analysis. Human Molecular Genetics, 15, 1539-1549. https:// doi.org/10.1093/hmg/ddl073.

Freeland, J. R., \& Petersen, S. D. (2011). Molecular ecology (2nd ed.). Wiley-Blackwell.

Guindalini, C., Scivoletto, S., Ferreira, R. G., Breen, G., Zilberman, M., Peluso, M. A., et al. (2005). Association of genetic variants in alcohol dehydrogenase 4 with alcohol dependence in Brazilian patients. The American Journal of Psychiatry, 162, 1005-1007. https://doi.org/10.1176/appi.ajp.162.5.1005.

Hakenewerth, A. M., Milikan, R. C., Rusyn, I., Herring, A. G., North, K. E., BarnholtzSloan, J. S., et al. (2011). Joint effects of alcohol consumption and polymorphisms in alcohol and oxidative stress metabolism genes on risk of head and neck cancer. Cancer Epidemiology, Biomarkers \& Prevention, 20, 2438-2449. https://doi.org/10.1158/1055-9965.EPI-11-0649.

Hartl, D. L., \& Clark, A. G. (2007). Principles of population genetics (4th ed.). Cambridge, MA: Harvard University.

Higuchi, S., Matsushita, S., Murayama, M., Takagi, S., \& Hayashida, M. (1995). Alcohol and aldehyde dehydrogenase polymorphisms and the risk for alcoholism. The American Journal of Psychiatry, 152, 1219-1221. https://doi.org/10.1176/ ajp.152.8.1219.

Instituto Brasileiro de Geografia e Estatística (IBGE). (2016) URL: http://www.ibge gov.br. Accessed 04.08.17.

Jorde, L. B. (2000). Linkage disequilibrium and the search for complex disease genes. Genome Research, 10, 1435-1444.

Kimura, Y., Nishimura, F. T., Abe, S., Fukunaga, T., Tanii, H., \& Saijoh, K. (2009). Polymorphisms in the promoter region of the human class II alcohol dehydrogenase (ADH4) gene affect both transcriptional activity and ethanol metabolism in Japanese subjects. The Journal of Toxicological Sciences, 34, 89-97.

Kuo, P., Kalsi, G., Prescott, C. A., Hodgkinson, C. A., Goldman, D., van den Oord, E. J. et al. (2008). Association of ADH and ALDH genes with alcohol dependence in the Irish Affected Sib Pair Study of alcohol dependence (IASPSAD) sample. Alcoholism: Clinical and Experimental Research, 32, 785-795. https://doi.org/ 10.1111/j.1530-0277.2008.00642 x.

Lee, S. L., Chau, G. Y., Yao, C. T., Wu, C. W., \& Yin, S. J. (2006). Functional assessment of human alcohol dehydrogenase family in ethanol metabolism: Significance of first-pass metabolism. Alcoholism: Clinical and Experimental Research, 30 1132-1142. https://doi.org/10.1111/j.1530-0277.2006.00139.x.

Li, N., Chang, W. C., Warui, D. M., Booker, S. J., Krebs, C., \& Bollinger, J. M. (2012). Evidence for only oxygenative cleavage of aldehydes to alk(a/e)nes and formate by cyanobacterial aldehyde decarbonylases. Biochemistry, 51, 7908-7916. https://doi.org/10.1021/bi300912n.

Luo, X., Kranzler, H. R., Zuo, L., Lappalainen, J., Yang, B. Z., \& Gelenter, J. (2006). ADH4 gene variation is associated with alcohol dependence and drug dependence in European Americans: Results from HWD tests and case-control association studies. Neuropsychopharmacology, 31, 1085-1095. https://doi.org/10.1038 sj.npp.1300925.

Macgregor, S., Lind, P. A., Bucholz, K. K., Hansel, N. K., Madden, P. A., Richter, M. M. et al. (2009). Associations of ADH and ALDH2 gene variation with self report alcohol reactions, consumption and dependence: An integrated analysis. $\mathrm{Hu}$ man Molecular Genetics, 18, 580-593. https://doi.org/10.1093/hmg/ddn372.

Meloni, J. N., \& Laranjeira, R. (2004). The social and health burden of alcohol abuse. Revista Brasileira de Psiquiatria, 26(Suppl 1), S7-S10. S1516-44462004000500003.
Meyers, J. L., Shmulewitz, D., Wall, M. M., Keyes, K. M., Aharonovich, E., Spivak, B., et al. (2015). Childhood adversity moderates the effect of ADH1B on risk for alcohol-related phenotypes in Jewish Israeli drinkers. Addiction Biology, 20 , 205-214. https://doi.org/10.1111/adb.12102.

Neumark, Y. D., Friedlander, Y., Thomasson, H. R., \& Li, T. K. (1998). Association of the $A D H 2 * 2$ allele with reduced ethanol consumption in Jewish men in Israel: A pilot study. Journal of Studies on Alcohol, 59, 133-139.

Nishimoto, I. N., Pinheiro, N. A., Rogatto, S. R., Carvalho, A. L., de Moura, R. P., Caballero, O. L., et al. (2004). Alcohol dehydrogenase 3 genotype as a risk factor for upper aerodigestive tract cancers. Archives of Otolaryngology-Head and Neck Surgery, 130, 78-82. https://doi.org/10.1001/archotol.130.1.78.

Peng, G. S., Yin, J. H., Wang, M. F., Lee, J. T., Hsu, Y. D., \& Yin, S. J. (2002). Alcohol sensitivity in Taiwanese men with different alcohol and aldehyde dehydrogenase genotypes. Journal of the Formosan Medical Association, 101, 769-774.

Prado, F. B., \& Caria, P. H. (2007). Morphological comparison between Brazilian's mandibles and populations from four continents. International Journal of Morphology, 25, 323-327.

Preuss, U. W., Ridinger, M., Rujescu, D., Samochowiec, J., Fehr, C., Wurst, F. M., et al. (2011). Association of ADH4 genetic variants with alcohol dependence risk and related phenotypes: Results from a larger multicenter association study. Addiction Biology, 16, 323-333. https://doi.org/10.1111/j.1369-1600.2010. 00236.x.

Rebello, A. S., \& Carvalho, M. G. (2008). Metodologia para estudo do polimorfismo do gene da enzima álcool desidrogenase. Revista de Ciências Médicas e Biológicas, 7, 163-168.

Rebello, A. S., Moura-Neto, R., \& Carvalho, M. G. (2011). Association study of the Ile349val polymorphism of the gene ADH1C and alcohol dependence. Jornal Brasileiro de Psiquiatria, 60. https://doi.org/10.1590/S0047-20852011000100002.

Rousset, F. (2008). genepop'007: a complete re-implementation of the genepop software for Windows and Linux. Molecular Ecology Resources, 8, 103-106. https://doi.org/10.1111/j.1471-8286.2007.01931.x.

Salujha, S. K., Chaudhury, S., Menon, P. K., Srivastava, K., \& Gupta, A. (2014). Allelic variants of $\mathrm{ADH}, \mathrm{ALDH}$ and the five factor model personality in alcohol dependence syndrome. Industrial Psychiatry Journal, 23, 44-51. https://doi.org/ 10.4103/0972-6748.144956.

Service, S., Sabatti, C., \& Freimer, N. (2007). Tag SNPs chosen from Hapmap perform well in several populations isolates. Genetic Epidemiology, 31, 189-194. https:// doi.org/10.1002/gepi.20201.

Silveira, C. M., Viana, M. C., Siu, E. R., de Andrade, A. G., Anthony, J. C., \& Andrade, L. H. (2011). Sociodemographic correlates of transitions from alcohol use to disorders and remission in the Sao Paulo megacity mental health survey, Brazil. Alcohol and Alcoholism, 46, 324-332. https://doi.org/10.1093/alcalc/ agr007.

Stenzel, A., Lu, T., Koch, W. A., Hampe, J., Guenther, S. M., De La Vega, F. M., et al. (2004). Patterns of linkage disequilibrium in the MHC region on human chromosome 6p. Human Genetics, 114, 377-385. https://doi.org/10.1007/s00439003-1075-5.

Stumpf, M. P. \& Goldstein, D. B. (2003). Demography, recombination hotspot intensity, and the block structure of linkage disequilibrium. Current Biology, 13, $1-8$.

Turchi, C., Piva, F., Solito, G., Principato, G., Buscemi, L., \& Tagliabracci, A. (2012). $\mathrm{ADH} 4$ intronic variations are associated with alcohol dependence: Results from an Italian case-control association study. Pharmacogenetics and Genomics, 22, 79-94. https://doi.org/10.1097/FPC.0b013e32834d05c8.

Vatansever, S., Tekin, F., Salman, E., Altintoprak, E., Coskunol, H., \& Akarca, U. S. (2015). Genetic polymorphisms of ADH1B, ADH1C and ALDH2 in Turkish alcoholics: Lack of association with alcoholism and alcoholic cirrhosis. Bosnian Journal of Basic Medical Sciences, 15, 37-41. https://doi.org/10.17305/ bjbms.2015.242.

Wall, T. L., Shea, S. H., Luczak, S. E., Cook, T. A., \& Carr, L. G. (2005). Genetic associations of alcohol dehydrogenase with alcohol use disorders and endophenotypes in white college students. Journal of Abnormal Psychology, 114, 456-465. https://doi.org/10.1037/0021-843X.114.3.456.

Wang, J., Wei, J., Xu, X., Pan, W., Ge, Y., Zhou, C., et al. (2014). Replication study of ESCC susceptibility genetic polymorphisms locating in the ADH1B-ADH1CADH7 cluster identified by GWAS. PloS One, 9, e94096. https://doi.org/ 10.1371/journal.pone.0094096.

Weiss, K. M., \& Clark, A. G. (2002). Linkage disequilibrium and the mapping of complex human traits. Trends in Genetics, 18, 19-24. 